\title{
Differential heat tolerance in nestlings suggests sympatric species may face different climate change risks
}

\author{
Inês Catry ${ }^{1,2 *}$, Teresa Catry ${ }^{3}$, Pedro Patto ${ }^{4}$, Aldina M. A. Franco ${ }^{2}$, Francisco Moreira ${ }^{1}$ \\ ${ }^{1}$ Centro de Ecologia Aplicada ‘Prof. Baeta Neves' and InBio - Rede de Investigação em Biodiversidade e Biologia Evolutiva, \\ Instituto Superior de Agronomia, Universidade de Lisboa, Tapada da Ajuda, 1349-017 Lisboa, Portugal \\ ${ }^{2}$ School of Environmental Sciences, University of East Anglia, Norwich NR4 7TJ, UK \\ ${ }^{3}$ Centro de Estudos do Ambiente e do Mar/Museu Nacional de História Natural e da Ciência, Universidade de Lisboa, \\ Rua da Escola Politécnica 58, 1250-102 Lisboa, Portugal \\ ${ }^{4}$ Departamento de Biologia Animal, Faculdade de Ciências da Universidade de Lisboa, Campo Grande, \\ 1749-016 Lisboa, Portugal
}

\begin{abstract}
For endotherms, a major threat of climate change will be the increasing frequency of extreme climate events, including heat waves. Thus, the ability of different species to tolerate high environmental temperatures is likely to have important consequences for ecology and population dynamics. We investigated the impacts of exposure to high temperatures on survival, mass gain and physiological stress of nestlings of 2 sympatric bird species subjected to the same climatic conditions in the Mediterranean basin. Results showed species-specific responses to high temperatures. Whilst hyperthermia or acute dehydration caused $36 \%$ mortality among lesser kestrels Falco naumanni, none occurred among European rollers Coracias garrulus. Within survivors, high maximum daily temperatures significantly reduced mass gain, especially among kestrels. Moreover, mass loss during heat events was shown to result in carry-over fitness costs only for lesser kestrels, by decreasing fledging condition and likely impacting post-fledging survival. High nest temperatures strongly elevated physiological stress levels of kestrels. Overall, rollers exhibited greater resilience to heat than kestrels, surviving nest temperatures up to $50^{\circ} \mathrm{C}$ and recovering from mass losses, suggesting that nestling development is flexible enough to cope with the constraints imposed by occasional heat waves. Although predicted increases in the frequency of extreme temperatures can accentuate lethal and sublethal fitness costs for both species, the higher thermal tolerance of rollers makes them more resilient. Our results highlight that sympatric species are not equally at risk when facing climate change and suggest that successfully predicting species response to global warming will require a better understanding of species-specific thermal tolerance.
\end{abstract}

KEY WORDS: Endotherms · Heat tolerance - Thermal range $\cdot$ Climate change $\cdot$ Nest-site microclimate $\cdot$ Lesser kestrel $\cdot$ European roller

\section{INTRODUCTION}

In hot environments, many species are regularly exposed to high environmental temperatures. When environmental temperatures rise above the thermoneutral zone (TNZ), endotherms use behavioural (e.g. reducing activity) and physiological (e.g. increasing evaporative water loss) adjustments to increase heat loss and to maintain relatively constant body temperature (Porter \& Kearney 2009, Angilletta et al. 2010, Boyles et al. 2011, Huey et al. 2012). Although these adjustments can help buffer the physiological impact of environmental change, exposure to high temperatures can incur high water and energy costs which 
ultimately can result in severe fitness costs and lethal hyperthermia (Welbergen et al. 2008, McKechnie \& Wolf 2010). Whilst most species are currently experiencing ambient temperatures well within their tolerance limits (Khaliq et al. 2014), climate change is predicted to bring species to experience more stressful, harmful or lethal weather events as the absolute number of days that lie outside their physiological tolerance is likely to increase (Parmesan et al. 2000). Therefore, one of the most deleterious consequences of climate change may be the predicted increases in the frequency, intensity and duration of extreme climate events, such as heat waves and droughts (Rahmstorf \& Coumou 2011, Rummukainen 2012). Evaluating the differential vulnerability of organisms to climate change is thus critical to predict which species may become threatened by climate change (Huey et al. 2012, Cahill et al. 2013).

Due to their small body size and predominantly diurnal habitats, birds can be particularly sensitive to increasing temperatures (McKechnie \& Wolf 2010). Previous studies have shown that, for some species, high temperatures may negatively impact birds' foraging patterns and efficiency (Wolf 2000, Tieleman \& Williams 2002, du Plessis et al. 2012), body condition (Wolf \& Walsberg 1996, du Plessis et al. 2012), breeding participation and productivity (Bolger et al. 2005, Ardia 2013), and survival (McKechnie \& Wolf 2010). Lethal and sub-lethal costs of high temperatures may be particularly acute for altricial avian offspring, which are more sensitive to thermal and hydric conditions at the nest (Lloyd \& Martin 2004). Developing nestlings have limited ability to regulate body temperatures (Visser 1998) and rates of energy expenditure are strongly influenced not only by air temperature but also by the thermal properties of the nest (Lloyd \& Martin 2004, Dawson et al. 2005, Ardia et al. 2010). Optimal development and growth requires an adequate thermal range, outside of which temperatures can alter nestling physiology, condition and survival (Dawson et al. 2005, Catry et al. 2011a, du Plessis et al. 2012, Ardia 2013, Cunningham et al. 2013, Salaberria et al. 2014). Moreover, nest microclimate and environmental conditions experienced by nestlings can have strong effects that can carry-over to later life-history stages (e.g. influencing postfledging survival; Greño et al. 2008), especially for relatively short-lived species (Smith \& Smith 2011), and thus influence the resilience of bird populations. Temperature-induced fitness costs are likely more important in latitudes where high temperatures are common, and where temperatures above the thermal tolerance of the birds could be more frequent, as occurs in the Mediterranean basin (Greño et al. 2008, Salaberria et al. 2014), considered a climate change hotspot (Giorgi 2006). In this area, climate change is predicted to bring important increases in mean temperatures and in the frequency of heat waves (Easterling et al. 2000, Santos \& Miranda 2006) and to have profound, although scarcely evaluated, ecological effects (Sala et al. 2000, EEA 2008).

In this paper, we assess the adaptive variation in heat-tolerance of 2 sympatric breeding species inhabiting a Mediterranean cereal steppe landscape: the lesser kestrel Falco naumanni and the European roller Coracias garrulus (hereafter roller). In particular, we investigate the effects of daily maximum temperature and nest-site microclimate on chick mass change over the nestling period, immune responsiveness and survival of nestlings. Because developing nestlings have poor thermoregulatory abilities, extreme temperatures may have important energetic and physiological impacts on lesser kestrels and rollers. We hypothesise that extreme temperatures during the nestling period can reduce rates of body mass gain through increased evaporative heat loss and can increase physiological stress, with implications for fledgling condition and survival. Moreover, as resilience to extreme high temperatures is predicted to vary according to species-specific thermoregulatory characteristics (Jiguet et al. 2006), we aim to investigate whether sympatric lesser kestrels and rollers are affected in the same way by high temperatures and compare species susceptibility to projected climate change.

\section{MATERIALS AND METHODS}

\subsection{Study site and species}

This study was carried out in the Portuguese main area of cereal steppes, the Castro Verde Special Protection Area (SPA), 37 $41^{\prime} \mathrm{N}, 8^{\circ} 05^{\prime} \mathrm{W}$. The region is classified as a meso-mediterranean bioclimatic stage (Rivas-Martínez 1981), with fairly cold winters and hot dry summers (30 to $35^{\circ} \mathrm{C}$ on average in July). The area hosts more than $80 \%$ of the national breeding populations of lesser kestrels and rollers (418-436 and 52-55 pairs, respectively; Catry et al. 2009, 2011b), 2 long-distance migratory species that winter in subSaharan Africa (Del Hoyo et al. 2001a,b). Lesser kestrels and rollers occupy cavities in abandoned rural buildings or artificial nesting structures (such as nest-boxes, clay pots or breeding walls) scattered in the treeless plains (Catry et al. 2009). Often the 2 spe- 
cies are found in the same building and may use the same nest-sites in alternate years. Lesser kestrels typically lay 4 to 5 eggs in April-May, incubation takes $28 \mathrm{~d}$, and nestlings fledge at $36 \mathrm{~d}$ (Del Hoyo et al. 2001a). Rollers lay 3 to 6 eggs mainly in May, hatching occurs after 17 to $19 \mathrm{~d}$, and chicks fledge at 25 to $30 \mathrm{~d}$ (Del Hoyo et al. 2001b). Data used in this study were collected during a long-term monitoring study of both populations.

\subsection{Nestling mass change, survival and physiological stress}

From late May to early July, we monitored 28 lesser kestrel nests (in 2009 and 2014) and 13 roller nests (only in 2014) to quantify rates of nestling mass change during the chick rearing period and to assess chick survival. Heat-induced chick mortality was assigned to chicks found dead with no sign of injuries, parasite infection, predation or starvation (see Catry et al. 2011a for further details on estimation of heatinduced mortality). Chicks were individually marked with coloured cable ties at hatching (frequently changed to allow tarsus growth) and ringed at approximately 2 wk of age. From hatchling to fledging, each nestling ( $\mathrm{n}=98$ and 51 lesser kestrels and rollers, respectively) was weighed using an electronic scale (to the nearest $0.1 \mathrm{~g}$ ) and wing length was measured (to the nearest $0.1 \mathrm{~mm}$ ) every $2 \mathrm{~d}$, always at the same hour. Change in body mass $(\Delta m)$ was calculated as the difference in nestling mass between 2 consecutive visits, thus being positive for mass gain and negative for mass loss. Nest typology included wooden nest-boxes, provided for both species amongst other artificial nest-types (Catry et al. 2009), and cavities in walls made of adobe, the traditional housebuilding material in the region (see Table A1 in the Appendix).

We used heterophil/lymphocyte ratios (H/L) as a haematological stress indicator to evaluate the physiological response of lesser kestrel nestlings to the nest microclimate. Leukocyte profiles, especially H/L ratio, have been widely used to assess immune function and stress in birds (reviewed in Davis et al. 2008). In 2013, during the nestling period, we collected 121 blood samples from 63 lesser kestrel nestlings $(>10$ d) at 32 nests where temperature inside the nest was being recorded. Some nestlings $(\mathrm{n}=38)$ were sampled more than once, with at least $1 \mathrm{wk}$ interval, to assess immune responsiveness under different temperatures. Blood samples $(<25 \mu \mathrm{l})$ were taken from the brachial vein in heparinised capillaries. Blood smears were made using the 2slide wedge technique (Clark et al. 2009); slides were air-dried, fixed with $96 \%$ ethanol, and stained with Giemsa solution (1/10) for $1 \mathrm{~h}$. The differential count of lymphocytes and heterophils was calculated as the percentage of all leukocytes. Leukocyte numbers per 10000 erythrocytes were obtained by counting the number of all erythrocytes in one microscopic visual field and multiplying it by the number of microscopic visual fields that were scanned in order to obtain 100 leukocytes (Lobato et al. 2005, Dehnhard et al. 2011). For each nestling, we recorded body mass ( $\mathrm{g}$ ), wing length $(\mathrm{mm})$, number of siblings, age and whenever possible, the sex.

\subsection{Nest-site microclimate and air temperatures}

To account for the impact of nest-type and location on nest microclimate, we deployed temperature dataloggers (micro-T DS1922L, accuracy of $\pm 0.5^{\circ} \mathrm{C}$, Ecotone) in all monitored nests in 2013 and 2014. External air temperatures were recorded by loggers placed outside, in shadow. All devices collected daily temperatures at $60 \mathrm{~min}$ intervals.

\subsection{Statistical analyses}

All analyses were conducted in the R statistic environment (R Development Core Team 2010). Nestling survival (binomial variable: alive/dead) within each 2 d interval in 2009 and 2014 was modelled as a function of maximum air temperature recorded within the same period using a generalized linear mixed model (GLMM) with a binomial error distribution and a logit-link function. Nest-type (wooden nest-box or adobe cavity) was also included as a predictor, and brood and nestling identity (nested within brood) were fitted as random factors.

The effect of maximum air temperature on body mass change $(\Delta \mathrm{m})$ of nestling lesser kestrels and rollers was assessed using generalized additive mixed models (GAMM), following Catry et al. (2011a). From hatchling, body mass change between $2 \mathrm{~d}$ interval visits was modelled using a Gaussian distribution and an identity-link function. Again, maximum temperature was taken as the higher temperature value registered within each $2 \mathrm{~d}$ interval. Other predictors (nestling age, brood size, nest-type and year, this last predictor only for lesser kestrels) were initially included in the models as they may influence nestling body mass; brood size was removed from the final 
model given its non-significant effect. Both brood and nestling identity (nested within broods) were included as random factors. All nestlings older than $18 \mathrm{~d}$ (rollers) and $25 \mathrm{~d}$ (lesser kestrels) were excluded from the model, as slight variations in chicks' weight close to fledgling date, not attributable to temperature, is often observed (Avilés \& Sánchez 1998, Catry et al. 2011a). Because dead nestlings were not weighed, data of mass loss in the 2-day period prior to death were not included. Similar models were developed to assess the effect of temperature on wing length changes of nestlings but produced no significant results; therefore these models are not presented. All models were fitted using the 'mgcv' package and the 'gamm' function (Wood 2006). A basis dimension of $k=4$ was set for the non-linear terms (age and maximum temperature) to allow some complexity in the function while providing a realistic prediction of temperature effects and avoiding over-fitting of the data. To further minimize the risks of over-fitting, a gamma value of 1.4 was set, as recommended by Wood (2006). Residuals of final models were visually inspected to ensure model assumptions were met.

To assess the impact of heat-induced body mass change $(\Delta m)$ on nestling fitness of both species at the age of fledging, we used a GLM (with a Guassian error distribution and an identity-link function) to examine the relationship between the amount of mass gained or lost during a heat event and residual body mass at fledging. Heat events were defined as periods of $\geq 2$ consecutive days with maximum temperatures $>37^{\circ} \mathrm{C}$. In our study area and during the nestling period, such days are fairly uncommon (average \pm SD: $1.97 \pm 2.35$ d per year in 1973-2014, www.ncdc.noaa.gov) and can markedly affect body condition and even cause fatal hyperthermia amongst chicks (see 'Results' and 'Discussion'). Nestling age at the heat event was included in the model to assess its relevance in mediating mass recoveries to the age of fledging. For each species, residual body mass was estimated from the residuals of nestling growth curves built using a non-linear regression to fit a logistic growth curve for the entire data set of nestlings weighed during the nestling period (Ricklefs 1983). Moreover, to assess the potential carry-over effects of heat events on later life stages, we investigate the impact of reduced body condition on post-fledging survival by comparing residual body mass at fledging of resighted (>1 yr after fledging) and nonresighted (and presumably dead) lesser kestrels in our study area between 2000 and 2012 (n = 3780). Residual body mass of fledglings was calculated from the residuals of a locally weighted regression LOESS of wing length on body mass. We did not use nestling growth curves since biometrics of most nestlings ringed during this period (2000-2012) were taken only once, at the age of fledging. Finally, heatinduced carry-over effects on post-fledging survival of rollers were not assessed given the few recoveries of birds ringed as chicks.

We examined relationships between leukocyte profiles of nestling lesser kestrels and nest-site temperature using GLMMs with a Gaussian error distribution and an identity-link function. Before the analyses, we normalized H/L ratios using a ln transformation. Because the time lag associated with the leukocyte response to the stressful event can be highly variable depending on the taxa (from hours to days, Davis et al. 2008), we estimated the mean and maximum nest temperature 6, 24 and $48 \mathrm{~h}$ before blood sampling. Since correlations between all temperature variables exceed 0.5 , we retained the variable that yield the lowest corrected Akaike's information criterion (AICc) value from univariate models. Thus, we removed all temperature variables except maximum temperature inside the nest in the $24 \mathrm{~h}$ preceding blood sampling. We also included age, sex, brood size and residual body mass (calculated from the residuals of a locally weighted regression LOESS between wing length and body mass, given that in 2013 growth curves were not measured; Rodríguez \& Bustamante 2003) as explanatory variables due to their potential impact on $\mathrm{H} / \mathrm{L}$ ratios. Given that siblings were not independent among themselves and that some nestlings were sampled more than once, we included brood and nestling (nested within brood) identity as random factors. Model selection followed Burnham \& Anderson (2002) using AICC adjusted for small sample sizes.

Relationships between nest microclimate and air temperature, and the effect of nest typology on nest microclimate were investigated using a GLMM, with nest set as a random factor.

\section{RESULTS}

\subsection{Heat-induced mortality and nest-site microclimate}

There was a significant effect of maximum air temperature on the probability of mortality of lesser kestrel nestlings (binomial GLMM: $\beta$-estimate $\pm \mathrm{SE}=$ $1.57 \pm 0.30, Z=5.18, \mathrm{p}<0.001$; Fig. 1) while no mortality occurred amongst rollers (Table A1 in the Appendix). Lesser kestrel mortality was biased to- 

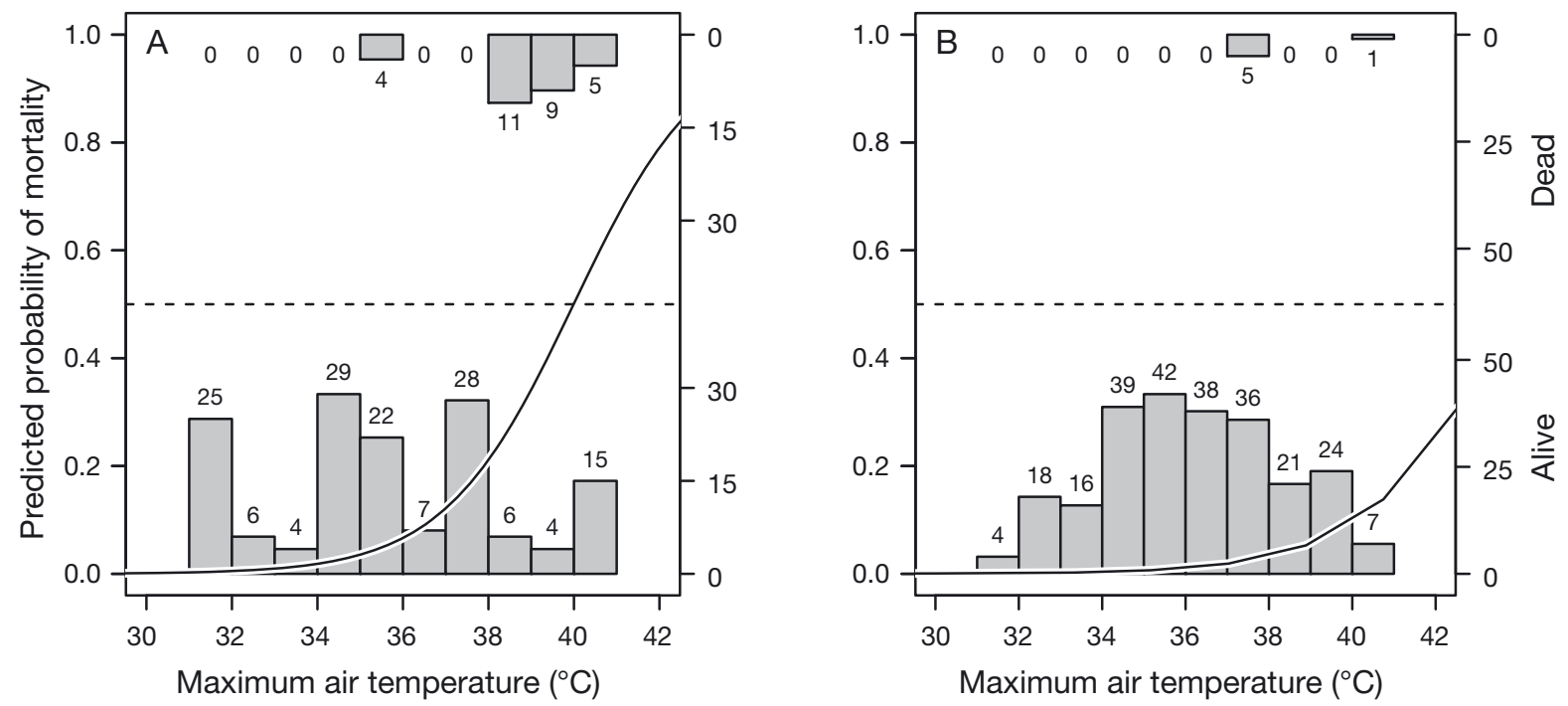

Fig. 1. Predicted probability of mortality of nestling lesser kestrels Falco naumanni according to maximum air temperatures in (A) wooden nest-boxes $(\mathrm{p}<0.001)$ and $(\mathrm{B})$ adobe cavities $(\mathrm{p}<0.05)$. Regression lines were fitted using binary logistic regressions. Dashed line: $50 \%$ probability of nestling mortality. Histograms: distribution of dead (top) and live (bottom) nestlings in each visit

wards nestlings from wooden nest-boxes $(\beta=5.05 \pm$ $2.24, Z=2.25, \mathrm{p}<0.05)$, with $>50 \%$ predicted probability of mortality when temperatures exceeds $40^{\circ} \mathrm{C}$, compared to only $13 \%$ in adobe cavities (Fig. 1). Daily maximum temperatures inside wooden nestboxes were, on average, $8.0 \pm 4.3^{\circ} \mathrm{C}$ higher than outside and significantly higher than inside adobe cavities (GLMM: $F_{1,24}=55.04, \mathrm{p}<0.001$ ), that were generally cooler than outside $\left(-1.3 \pm 2.8^{\circ} \mathrm{C}\right.$, Fig. 2). The interaction between temperature and nest-type was significant $\left(F_{1,713}=18.22\right.$, $\left.\mathrm{p}<0.001\right)$, showing that nest-boxes warm up faster with increasing air temperatures than adobe cavities (Fig. 2). No differences were found for nest-site temperatures between nests occupied by lesser kestrels and rollers $(p=0.4)$.

\subsection{Nestling mass change and carry-over fitness costs}

Results of the GAMM models show a speciesspecific response to increasing air temperatures (see Table A2 in the Appendix, Fig. 3). While among lesser kestrels rates of mass gain significantly decreased with increasing temperatures in both wooden nest-boxes (estimated degrees of freedom [edf] $=2.56$ and 1.68, $F=27.7$ and 31.9, $p<0.001$ for 2009 and 2014, respectively) and adobe cavities (edf $=2.95$ and $1.0, F=46.5$ and $14.2, \mathrm{p}<0.001$ for 2009 and 2014, respectively), rollers were only affected in wooden nest-boxes (edf $=2.38, F=25.0, p<0.001$ ), and not at cooler adobe cavities (edf $=1.00, F=0.35$, $\mathrm{p}=0.491$ ). Air temperature thresholds above which mass gain rates are predicted to decrease were lower in lesser kestrels than in rollers occupying nest-boxes (Fig. 3), suggesting a higher vulnerability of lesser kestrels to increasing temperatures. Although the effect of rising temperatures on rates of mass gain among lesser kestrels showed some inter-annual variation (as visible in the shape of the model curves), this relationship was significant and followed the same direction in both years (Table A2, Fig. 3). As expected, age was an important predictor of nestling mass change for both species (edf $=2.98$ and 2.89, $F=138.9$ and 58.8, $\mathrm{p}<0.001$ for lesser kestrels and rollers, respectively). Overall, temperature and age explained $54 \%$ of the variance in body mass change of both species (Table A2).

Body mass change during a heat event significantly affected residual body mass at fledging of lesser kestrels $\left(\beta=0.69 \pm 0.15, F_{1,41}=21.65, \mathrm{p}<0.001\right.$, $\left.\mathrm{R}^{2}=0.35\right)$, but not of rollers $\left(\beta=0.01 \pm 0.15, F_{1,34}=\right.$ $0.009, \mathrm{p}=0.92$ ), showing that lesser kestrels, contrarily to rollers, do not recover totally from previous mass losses during growth (Fig. 4), regardless of nestling age at the time of the heat event ( $p>0.05)$. Heat events can thus impact post-fledging survival given that significant differences between residual body mass at fledging of resighted (mean $=3.62 \mathrm{~g}$ ) and non-resighted $(-0.34 \mathrm{~g})$ nestling lesser kestrels in our study area between 2000 and $2012(t=-4.53$, $\mathrm{df}=3778, \mathrm{p}<0.001$ ) suggest that heavier fledglings might have higher survival and return probabilities than lighter ones. 


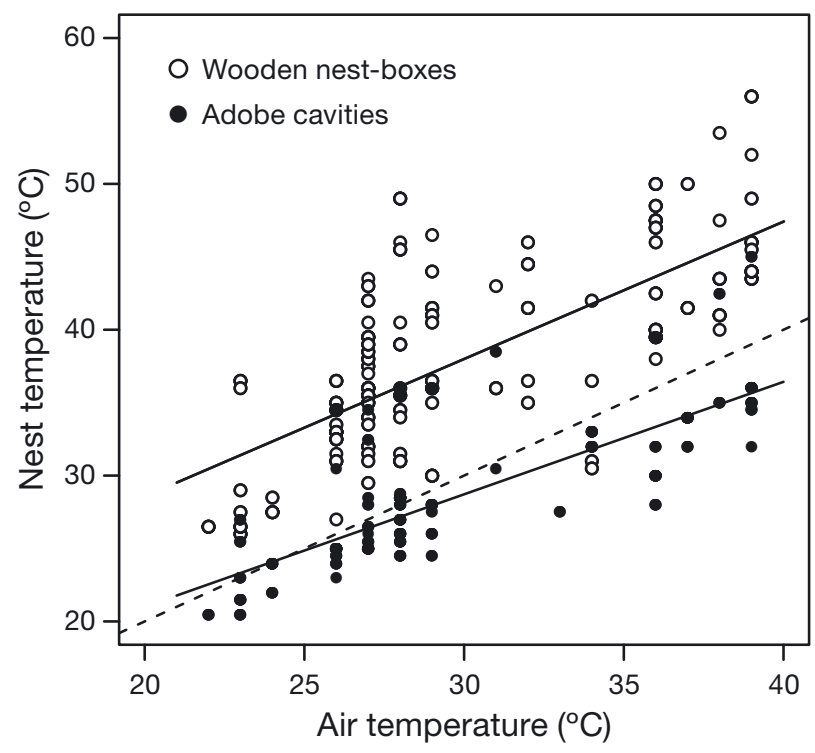

Fig. 2. Effect of nest typology on nest microclimate of lesser kestrels Falco naumanni and rollers Coracias garrulus. Solid lines: significant relationships between nest and air temperatures. Significantly higher temperatures and a faster warming rate occurred in wooden nest-boxes than in adobe cavities. Points below the dashed line: nests with cooler microclimates than outside air temperatures

\subsection{Physiological stress}

We found a strong positive effect of increasing nest temperatures on H/L ratios, i.e. physiological stress levels of lesser kestrel nestlings increased with temperature (Table 1, see Fig. A1 in the Appendix). Moreover, H/L ratios of nestlings were negatively and significantly associated with residual body mass (Table 1, Fig. A1). Both predictors entered the model with the lowest AICc value at very high selection probabilities, with maximum temperature $24 \mathrm{~h}$ be-

Table 1. Top 3 generalized linear mixed models (GLMM) for the heterophil/ lymphocyte (H/L) ratio in nestling lesser kestrels. Models are ranked according to the Akaike information criterion corrected for small sample sizes (AICC). $\Delta \mathrm{AICc}=\mathrm{AICc}$ differences between a particular model and the best-fitting model. Akaike weights $(\omega i)=$ contribution of each model to the average of all candidate models. Coefficients $( \pm \mathrm{SE})$ are shown for variables included in a particular model while blank spaces represent the exclusion of variables. $\Sigma \omega i$ $=$ for each variable, the sums of $\omega i$ for all possible models in which the predictor variable was included, thus reflecting the variable's relative importance

\begin{tabular}{|lcccccccc|}
\hline & \multicolumn{2}{c}{ Variables } & & & & & & \\
\cline { 1 - 3 } Model & $\begin{array}{c}\text { Max. nest } \\
\text { temperature }\end{array}$ & $\begin{array}{c}\text { Residual } \\
\text { body mass }\end{array}$ & Age & $k$ & AICc & $\Delta$ AICC & $\omega i$ \\
\hline 1 & $0.04 \pm 0.01$ & $-0.02 \pm 0.005$ & & 6 & 309.8 & 0.00 & 0.73 \\
2 & $0.06 \pm 0.01$ & $-0.02 \pm 0.005$ & $-0.03 \pm 0.01$ & 7 & 313.7 & 3.96 & 0.10 \\
3 & $0.05 \pm 0.01$ & & & 5 & 314.4 & 4.63 & 0.07 \\
$\Sigma \omega i$ & 0.97 & 0.92 & 0.11 & & & & \\
\hline
\end{tabular}

fore sampling having the largest relative importance compared to residual body mass $(\Sigma \omega i=0.97$ and 0.92 , respectively, Table 1).

\section{DISCUSSION}

Large scale heat-related die-offs due to extreme weather events have occasionally been documented and highlight one important, yet understudied, threat that climate change poses to endotherms (Salzman 1982, Parmesan et al. 2000, Welbergen et al. 2008, McKechnie \& Wolf 2010). Evaluating the responsiveness of species to climatic perturbations that take place over a short time scale, during which other non-climatic variables remain essentially unchanged, constitutes a good approach to investigate species susceptibility to climate change (Jiguet et al. 2006). Here, we took advantage of heat events during 2 breeding seasons to assess, under natural conditions, the impact of temperature anomalies on nestling fitness of 2 sympatric breeding species. We show that optimal nestling development requires an adequate thermal range, outside which temperatures can alter nestling physiology, body condition and survival.

\subsection{Heat-induced mortality, nestling mass change and physiological stress}

On hot days, nestlings face a physiological conflict between evaporating water to maintain body temperature below lethal limits, and the need to conserve water and avoid dehydration (Cunningham et al. 2013, Salaberria et al. 2014). Hyperthermia and/or acute dehydration were the likely causes of death for 35 out of $98(36 \%)$ nestling lesser kestrels monitored every 2 d in 2009 and 2014. To the best of our knowledge, the physiological response of lesser kestrels and rollers to high temperatures has never been studied; therefore the upper critical limit of their TNZ is unknown. Fatal hyperthermia among lesser kestrels occurred mainly when air and nest temperatures exceeded 37 and $44^{\circ} \mathrm{C}$, respectively. Exposed to the same outside temperature, nestling rollers faced nest temperatures up to $50^{\circ} \mathrm{C}$, but none perished as a consequence of heat events. Although heat-induced mortality of nestling lesser kestrels was 

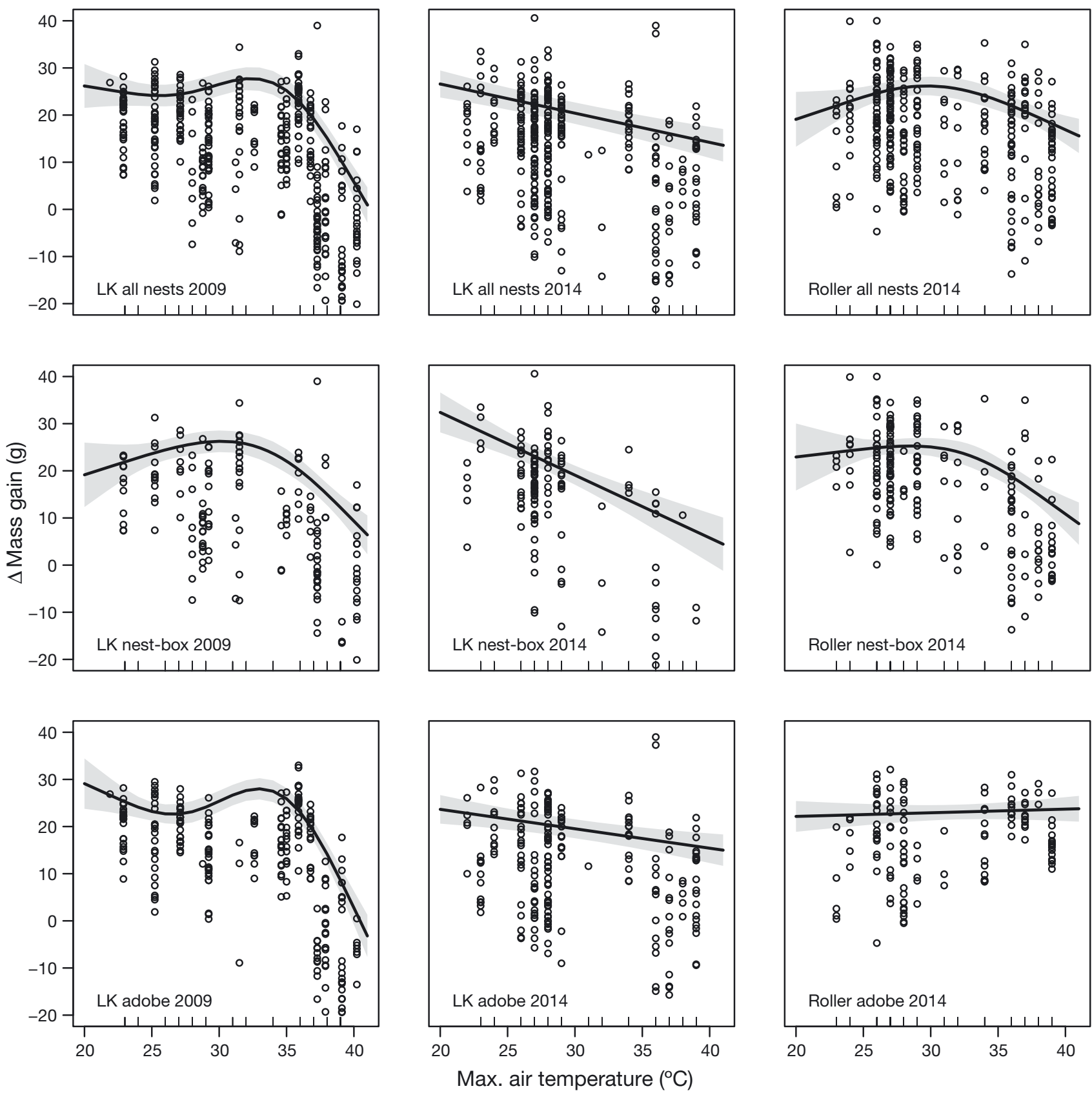

Fig. 3. Predicted values (solid lines) and $95 \% \mathrm{CI}$ (shaded areas) of body mass change $(\Delta m)$ in nestling lesser kestrels Falco naumanni (LK; 2009 and 2014) and rollers Coracias garrulus (2014) as a function of maximum air temperature $\left({ }^{\circ} \mathrm{C}\right)$ and nest-type (wooden box, adobe). Fitted curves were predicted by the inferred generalised additive mixed model (GAMM) coefficients using the actual range of values for the predictor of interest and mean values for the other variables (age). $x$-axis ticks: location of observations (points) along the predictors

recorded occasionally in the last $12 \mathrm{yr}$ of our monitoring programme, reductions in offspring numbers due to very hot days is probably underestimated. Indirect mortality (when chicks force themselves outside the nests due to high temperatures and likely die from predation or starvation) is hard to identify even with regular visits and, given that hot days are more fre- quent in late June or July, it is easy to misclassify mortality as early fledgling (Catry et al. 2011a). For instance, in 2012, during a $3 \mathrm{~d}$ period with temperatures exceeding $39^{\circ} \mathrm{C}$, more than 60 nestlings were collected alive (and rescued from death) from the ground, many of them being close to the age of fledging (Fig. 5; Barosa et al. 2012). 


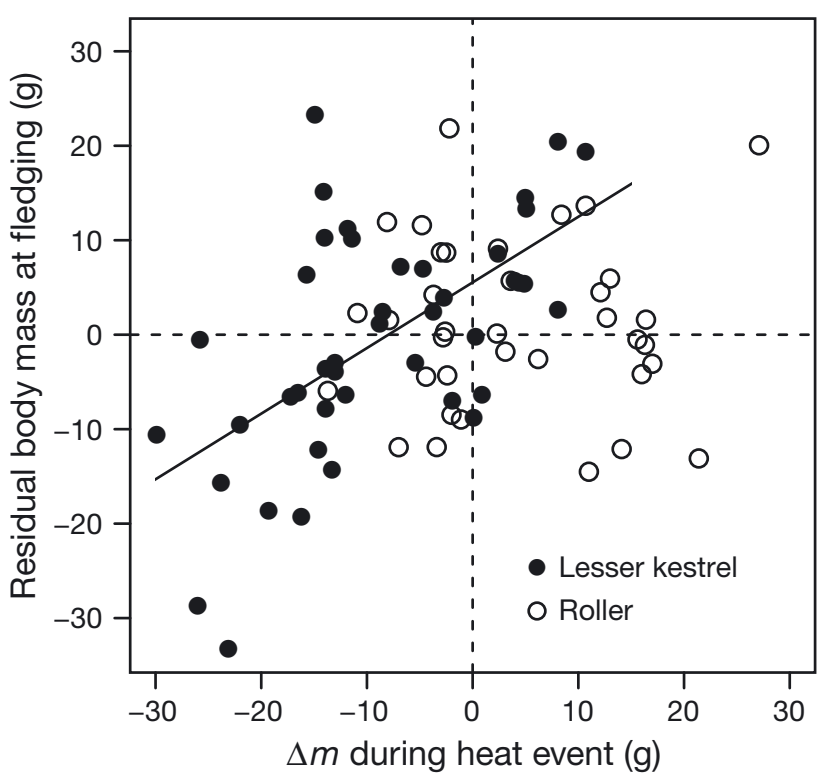

Fig. 4. Effect of heat events (measured as body mass change, i.e. $\Delta m=$ mass gain or loss) on the residual body mass of lesser kestrels Falco naumanni $(\mathrm{p}<0.001)$ and rollers Coracias garrulus $(\mathrm{p}=0.92)$ at fledging. Residual body mass was calculated from the residuals of a regression of wing length on body mass

During hot days, nestling mass gain declined significantly, whilst no changes in wing length were detected. Lesser kestrels lost up to $30 \mathrm{~g}(27 \%)$ and rollers up to $14 \mathrm{~g}(10 \%)$ of body mass, suggesting a direct physiological effect of thermoregulation on body condition. When temperatures deviate from the TNZ, endotherms must dissipate heat, mainly through evaporative water loss (Huey et al. 2012) which can explain the observed changes in body mass. Previous studies showed that small bird species, even when inactive in shaded sites, can experience rates of evaporative water loss of $>5 \%$ body mass $\mathrm{h}^{-1}$, conditions under which they rapidly reach their limits of dehydration tolerance (Wolf \& Walsberg 1996). Reductions in body mass were unlikely mediated by reduced parental provisioning rates, as suggested by comparison of prey delivery rates to nestling lesser kestrels during hotter and cooler periods (Catry et al. 2011a) and by observed contrasting impacts of temperature on nestling rollers exposed to different microclimates (high temperature reduced mass gain only at hotter nests, this study). Finally, observed year-specific responses of lesser kestrels to temperature suggest that responses to environmental changes are complex and may be mediated by other factors (e.g. annual variation in food availability) influencing species vulnerability to climate.
Body condition at fledging has been often shown to influence post-fledging survival as a carry-over effect from the pre-fledging period (e.g. Greño et al. 2008, Vitz \& Rodewald 2011, Blomberg et al. 2014). Our analyses for lesser kestrels seem to agree with these findings, although such results should be treated with caution as non-resighted fledglings could recruit outside the study area and consequently be missed. Moreover, our results suggest that temperature, namely the occurrence of heat events, may mediate this carry-over effect, given that observed strong effects of high temperatures on nestling growth were reflected in their fledging condition. Contrarily to lesser kestrels, fledgling rollers recovered from heat-induced reductions on body mass. Whether rollers have a greater resilience or ability to recover from climatic perturbations, or this is only a result of the weaker impact of maximum temperature on mass gain, is unknown. In any case, although rollers may compensate for mass losses by accelerating growth rates when conditions improve, this can eventually carry costs later in life (Metcalfe \& Monaghan 2001).

Heat stress due to increased temperature and water deprivation elevated the number of heterophils and depressed the number of lymphocytes in nestling lesser kestrels. H/L ratios positively correlated with the severity of nest-site microclimate, independently of the nestling age, suggesting that this parameter is a good indicator of heat-induced physiological stress. Lower physiological and immunological condition of nestlings can also carry-over fitness costs (e.g. through decreased parasite defense), likely impacting post-fledging survival (Lobato et al. 2005, Hylton et al. 2006, Bowers et al. 2014).

\subsection{Contrasting vulnerability of lesser kestrels and rollers to high temperatures}

Rollers exhibited greater resilience to heat than lesser kestrels, surviving nest temperatures approaching $50^{\circ} \mathrm{C}$ and recovering from mass losses, suggesting that nestling development is plastic enough to buffer the constraints imposed by occasional hot days. Candidate traits that might explain the contrasting sensitivity of lesser kestrel and rollers include physiological tolerance and ecological traits, such as behaviour (Jiguet et al. 2006, Williams et al. 2008). However, inside the nest, nestlings have limited capacity of behavioural buffering; therefore thermal tolerance is likely the main trait determining species vulnerability to increasing temperatures. To the best of our knowledge, the physiological response of 


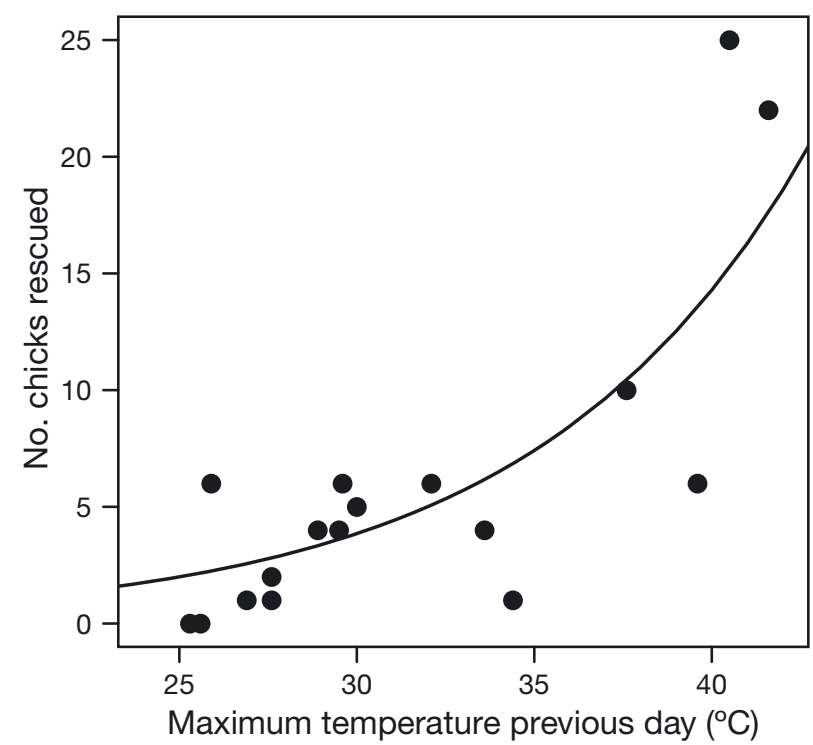

Fig. 5. Relationship between daily maximum air temperatures $\left({ }^{\circ} \mathrm{C}\right)$ and number of nestling lesser kestrels Falco naumanni collected from the ground during a rescue campaign in 2012. The smooth curve (black line) was fitted by an exponential model $\left(F_{1,15}=20.42, \mathrm{p}<0.001, \mathrm{R}^{2}=0.58\right)$. On very hot days, nestlings are forced out of their nests to avoid lethal temperatures there and ultimately die from dehydration, starvation or predation

lesser kestrels and rollers to high temperatures has never been studied, and thus the upper critical limit of their TNZ is unknown. Nevertheless, our results suggest that lesser kestrels might have a narrower TNZ or a lower upper critical limit in comparison to rollers. Thermoregulation among nestling rollers may also be facilitated by morphological traits. At moderate air temperatures, water loss in birds is controlled by respiratory and cutaneous components (Wolf \& Walsberg 1996). As air temperature increases, however, and due to the insulation characteristic of feathers, the temperature of the feather-covered body surface approaches air temperature; hence, this surface hardly contributes to overall heat loss and respiratory evaporative cooling becomes the dominant form of heat dissipation (Dawson 1982, Wolf \& Walsberg 1996). Being featherless can thus provide heat tolerance under moderate and acute heat waves enabling featherless birds to maintain normal body temperatures under hot conditions (Azoulay et al. 2011). While rollers hatch naked (they have closed spiny feather sheaths after $13 \mathrm{~d}$ that open after $17 \mathrm{~d}$; Del Hoyo et al. 2001b), which may facilitate heat exchange with the environment, hatchling lesser kestrels are covered in white down feathers, a thermal insulator that likely limits heat dissipation in hot nests. Nestling kestrels may avoid overheating by increas- ing their respiratory frequency, i.e. through panting, a behaviour that was often observed in nestling lesser kestrels but not in rollers. The advantage of cutaneous evaporative water loss over panting is that no extra metabolic heat is produced by the activity of the respiratory or buccal muscles, and moreover the $\mathrm{CO}_{2}$ washout in the lungs is avoided, preventing alkalosis, which can lead to death (Maclean 2011).

\subsection{Potential consequences of global warming}

The frequency of hot days (max. temperature $>37^{\circ} \mathrm{C}$ ) in our study area has increased since the 1970s and further increases are predicted (I. Catry unpubl. data, Santos \& Miranda 2006). Future climatic changes can worsen the lethal and sublethal heat-induced fitness costs reported for lesser kestrels and rollers. In general, population dynamics of short-lived species are highly sensitive to variations in factors regulating reproductive output (Sæther \& Bakke 2000). In warm countries such as Portugal, a sustained drop in the breeding success of lesser kestrels due to heatinduced nestling mortality could lead to population declines within short temporal scales (see Catry et al. 2011a). This result strongly differs from the findings for the northern edge of the species distribution where a general positive impact of warmer climate on lesser kestrels was described (Mihoub et al. 2012). Contrasting results have been found within the same species and different populations across several geographic areas due to the spatial-temporal variation in climate (Both \& te Marvelde 2007). Apparent higher thermal tolerance of rollers may delay the impacts of increasing temperatures on this population, although the ongoing effects of mass loss on post-fledging survival need further investigation. These results highlight the need for a large-scale assessment to determine how climate change will affect the reproductive performance of species throughout their ranges. Moreover, the continuity of a monitoring programme could also help achieving a better understanding of the importance of other external factors (e.g. laying time, feeding conditions, parental quality) that might influence nestlings' sensitivity to heat. Regarding species conservation and given that both lesser kestrels and rollers are highly dependent on the availability of artificial nests (Catry et al. 2009, 2011b), resilience to climate change may be enhanced through the provisioning of nest-sites that have the potential to buffer climate, decreasing nestlings' exposure to extreme climate events. Finally, in regions that can achieve high temperatures during the breeding 
period, future provisioning of wooden-nest boxes should be avoided.

Species are not equally at risk when facing climate warming. Our results highlight that attempts to understand species' vulnerability to predicted global warming must (1) be built from a robust understanding of species-specific sensitivity and response to temperature, (2) require consideration of the vulnerability of each life-cycle stage, (3) account for microclimate temperatures, which can deviate significantly from macroclimate temperatures and (4) account for changing frequency of high-temperature events, rather than a gradual rise in average temperature alone.

Acknowledgements. I.C. and T.C. benefited from post-doctoral grants from Fundação para a Ciência e Tecnologia (SFRH/ BPD/76514/2011 and SFRH/BPD/102255/2014, respectively). Part of the funding in 2012 and 2014 was provided by the European Union (FP7) Project DROUGHTR\&SPI (contract 282769). The manuscript benefited from the comments of 3 anonymous referees.

\section{LITERATURE CITED}

Angilletta MJ Jr, Cooper BS, Schuler MS, Boyles JG (2010) The evolution of thermal physiology in endotherms. Front Biosci E2:861-881

> Ardia DR (2013) The effects of nestbox thermal environment on fledging success and haematocrit in Tree Swallows. Avian Biol Res 6:99-103

- Ardia DR, Pérez JH, Clotfelter ED (2010) Experimental cooling during incubation leads to reduced innate immunity and body condition in nestling tree swallows. Proc R Soc B 277:1881-1888

Avilés JM, Sánchez A (1998) Crecimiento de los pollos de carraca (Coracias garrulus) en medios esteparios de Extremadura (SO península ibérica): influencia de las precipitaciones. Misc Zool 21:1-7

Azoulay Y, Druyan S, Yadgary L, Hadad Y, Cahaner A (2011) The viability and performance under hot conditions of featherless broilers versus fully feathered broilers. Poult Sci 90:19-29

Barosa L, Sanches AR, Estanque B, Marques C, Lousa H, Constantino R, Alcazar R (2012) Implementação de um programa de recuperação para aves estepárias. Techn Rep LIFE07/NAT/P/654, Lisboa

Blomberg EJ, Sedinger JS, Gibson D, Coates PS, Casazza ML (2014) Carryover effects and climatic conditions influence the postfledging survival of greater sage-grouse. Ecol Evol 4:4488-4499

$>$ Bolger DT, Patten MA, Bostock DC (2005) Avian reproductive failure in response to an extreme climatic event. Oecologia 142:398-406

Both C, te Marvelde L (2007) Climate change and timing of avian breeding and migration through Europe. Clim Res 35:93-105

Bowers EK, Hodges CJ, Forsman AM, Vogel LA and others (2014) Neonatal body condition, immune responsiveness, and hematocrit predict longevity in a wild bird population. Ecology 95:3027-3034
Boyles JG, Seebacher F, Smit B, McKechnie AE (2011) Adaptive thermoregulation in endotherms may alter responses to climate change. Integr Comp Biol 51:676-690

Burnham KP, Anderson DR (2002) Model selection and multimodel inference: a practical information-theoretic approach, 2nd edn. Springer, New York, NY

Cahill AE, Aiello-Lammens ME, Fisher-Reid MC, Hua X and others (2013) How does climate change cause extinction? Proc R Soc B 280:20121890

Catry I, Alcazar R, Franco AMA, Sutherland WJ (2009) Identifying the effectiveness and constraints of conservation interventions: a case study of the endangered Lesser Kestrel. Biol Conserv 142:2782-2791

> Catry I, Franco AMA, Sutherland WJ (2011a) Adapting conservation efforts to face climate change: modifying nestsite provisioning for Lesser Kestrels. Biol Conserv 144: 1111-1119

Catry I, Silva JP, Cardoso A, Martins A and others (2011b) Distribution and population trends of the European Roller in pseudo-steppe areas of Portugal: results from a census in sixteen SPAs and IBAs. Airo 21:3-14

Clark P, Boardman W, Raidal S (2009) Atlas of clinical avian hematology. Wiley-Blackwell, Oxford

Cunningham SJ, Martin RO, Hojem CL, Hockey PAR (2013) Temperatures in excess of critical thresholds threaten nestling growth and survival in a rapidly-warming arid savanna: a study of common fiscals. PLoS ONE 8:e74613

> Davis AK, Maney DL, Maerz JC (2008) The use of leukocyte profiles to measure stress in vertebrates: a review for ecologists. Funct Ecol 22:760-772

Dawson WR (1982) Evaporative losses of water by birds. Comp Biochem Physiol A Comp Physiol 71:495-509

> Dawson WR, Lawrie CC, O'Brien EL (2005) The importance of microclimate variation in determining size, growth and survival of avian offspring: experimental evidence from a cavity nesting passerine. Oecologia 144:499-507

> Dehnhard N, Quillfeldt P, Hennicke JC (2011) Leucocyte profiles and H/L ratios in chicks of Red-tailed Tropicbirds reflect the ontogeny of the immune system. J Comp Physiol B 181:641-648

Del Hoyo J, Elliott A, Sargatal J (2001a) Handbook of the birds of the world, Vol 2. New World Vultures to Guineafowl. Lynx Edn, Barcelona

Del Hoyo J, Elliott A, Sargatal J (2001b) Handbook of the birds of the world, Vol 6. Mousebirds to Hornbills. Lynx Edn, Barcelona

> du Plessis KL, Martin RO, Hockey PAR, Cunningham SJ, Ridley AR (2012) The costs of keeping cool in a warming world: implications of high temperatures for foraging, thermoregulation and body condition of an arid zone bird. Glob Change Biol 18:3063-3070

Easterling DR, Meehl GA, Parmesan C, Changnon SA, Karl TR, Mearns LO (2000) Climate extremes: observations, modeling and impacts. Science 289:2068-2074

EEA (Environmental Agency) (2008) Impacts of Europe's changing climate: 2008 indicator-based assess. EAA No. 4/2008, Copenhagen

Giorgi F (2006) Climate change hot-spots. Geophys Res Lett 33:08707

> Greño JL, Belda EJ, Barba E (2008) Influence of temperatures during the nestling period on post-fledging survival of great tit Parus major in a Mediterranean habitat. J Avian Biol 39:41-49

Huey RB, Kearney MR, Krockenberger A, Holtum JAM, Jess M, Williams SE (2012) Predicting organismal vulnerabil- 
ity to climate warming: roles of behaviour, physiology and adaptation. Philos Trans R Soc Lond B 367:1665-1679

Hylton RA, Frederick PC, de la Fuente TE, Spalding MG (2006) Effects of nestling health on postfledging survival of wood storks. Condor 108:97-106

Jiguet F, Julliard R, Thomas CD, Dehorter O, Newson SE, Couvet D (2006) Thermal range predicts bird population resilience to extreme high temperatures. Ecol Lett 9: 1321-1330

Khaliq I, Hof C, Prinzinger R, Böhning-Gaese K, Pfenninger $M$ (2014) Global variation in thermal tolerances and vulnerability of endotherms to climate change. Proc R Soc B 281:20141097

Lloyd JD, Martin TE (2004) Nest-site preference and maternal effects on offspring growth. Behav Ecol 15:816-823

Lobato E, Moreno J, Merino S, Sanz J, Arriero E (2005) Haematological variables are good predictors of recruitment in nestling pied flycatchers (Ficedula hypoleuca). Ecoscience 12:27-34

Maclean GL (2011) Ecophysiology of desert birds. Springer, Berlin

McKechnie AE, Wolf BO (2010) Climate change increases the likelihood of catastrophic avian mortality events during extreme heat waves. Biol Lett 6:253-256

Metcalfe NB, Monaghan P (2001) Compensation for a bad start: grow now, pay later? Trends Ecol Evol 16:254-260

Mihoub JB, Mouawad NG, Pilard P, Jiguet F, Low M, Teplitsky C (2012) Impact of temperature on the breeding performance and selection patterns in lesser kestrels Falco naumanni. J Avian Biol 43:472-480

Parmesan C, Root TL, Willig M (2000) Impacts of extreme weather and climate on terrestrial biota. Bull Am Meteorol Soc 81:443-450

Porter WP, Kearney M (2009) Size, shape and the thermal niche of endotherms. PNAS 106:19666-19672

R Development Core Team (2010) R: a language and environment for statistical computing. $\mathrm{R}$ Foundation for Statistical Computing, Vienna

Rahmstorf S, Coumou D (2011) Increase of extreme events in a warming world. PNAS 108:17905-17909

Ricklefs RE (1983) Avian postnatal development. In: Farner DS, King JR, Parkes KC (eds) Avian biology. Academic Press, New York, NY, p 1-83

Rivas-Martínez S (1981) Les étages bioclimatiques de la végétation de la Peninsule Ibérique. An Jardin Botanico Madr 1979 37:251-268

Rodríguez C, Bustamante J (2003) The effect of weather on lesser kestrel breeding success: Can climate change explain historical population declines? J Anim Ecol 72: 793-810

Rummukainen M (2012) Changes in climate and weather extremes in the 21st century. WIREs Clim Chang 3: $115-129$

Sæther BE, Bakke $\varnothing$ (2000) Avian life history variation and contribution of demographic traits to the population growth rate. Ecology 81:642-653

Sala OE, Chapin III FS, Armesto JJ, Berlow E and others (2000) Global diversity scenarios for the year 2100. Science 287:1770-1774

Salaberria C, Celis P, López-Rull I, Gil D (2014) Effects of temperature and nest heat exposure on nestling growth, dehydration and survival in a Mediterranean holenesting passerine. Ibis 156:265-275

Salzman AG (1982) The selective importance of heat stress in gull nest location. Ecology 63:742-751

Santos FD, Miranda P (2006) Alterações climáticas em Portugal: cenários, impactos e medidas de adaptacão. Project SIAM II. Gradiva, Lisbon

Smith TM, Smith RL (2011). Elements of ecology. Benjamin Cummings Publishing, San Francisco, CA

Tieleman BI, Williams JB (2002) Effects of food supplementation on behavioural decisions of hoopoe-larks in the Arabian Desert: balancing water, energy and thermoregulation. Anim Behav 63:519-529

Visser GH (1998) Development of temperature regulation. In: Starck JM, Ricklefs RE (eds) Avian growth and development: evolution within the altricial-precocial spectrum. Oxford University Press, Oxford, p 117-150

Vitz AC, Rodewald AD (2011) Influence of condition and habitat use on survival of post-fledging songbirds. Condor 113:400-411

Welbergen JA, Klose SM, Markus N, Eby P (2008) Climate change and the effects of temperature extremes on Australian flying-foxes. Proc R Soc B 275:419-425

Williams SE, Shoo LP, Isaac JL, Hoffmann AA, Langham G (2008) Towards an integrated framework for assessing the vulnerability of species to climate change. PLoS Biol 6:e325

Wolf BO (2000) Global warming and avian occupancy of hot deserts: a physiological and behavioral perspective. Rev Chil Hist Nat 73:395-400

Wolf BO, Walsberg GE (1996) Partitioning respiratory and cutaneous evaporative water loss during heat stress in a small bird. J Exp Biol 199:451-457

Wood S (2006) Generalized additive models: an introduction with R. CRC press, Boca Raton, FL 
Appendix. Heat-induced mortality and generalised additive model of body mass change $(\Delta m)$ in lesser kestrels Falco naumanni and rollers Coracias garrulus, as well as relationship between heterophil/lymphocyte (H/L) ratios (ln-transformed) and maximum nest temperature

Table A1. Heat-induced nestling mortality (expressed as absolute values and with proportions in parentheses) of lesser kestrels Falco naumanni (in 2009 and 2014) and rollers Coracias garrulus (in 2014) in wooden nest-boxes and adobe cavities

\begin{tabular}{|c|c|c|c|c|c|c|c|c|c|c|}
\hline & \multicolumn{2}{|c|}{ Nestling mortality } & \multicolumn{2}{|c|}{ Number of chicks } & \multicolumn{2}{|c|}{ Number of nests } & \multicolumn{4}{|c|}{ Nest orientation } \\
\hline & Nest-box & Adobe & Nest-box & Adobe & Nest-box & Adobe & ${ }^{\circ} \mathrm{N}$ & ${ }^{\circ} \mathrm{E}$ & ${ }^{\circ} \mathrm{S}$ & ${ }^{\circ} \mathrm{W}$ \\
\hline Lesser kestrel & $29(0.55)$ & $6(0.13)$ & 53 & 45 & 16 & 12 & 8 & 7 & 6 & 7 \\
\hline Roller & $0(0.00)$ & $0(0.00)$ & 31 & 20 & 8 & 5 & 2 & 4 & 3 & 4 \\
\hline
\end{tabular}

Table A2. Generalised additive mixed model (GAMM) of body mass change $(\Delta m)$ in nestling lesser kestrels Falco naumanni and rollers Coracias garrulus as a function of maximum air temperature $\left({ }^{\circ} \mathrm{C}\right)$, nest-type (wooden nest box, adobe), age and year. $\mathbf{s}(.)=$. predictors fitted as non-parametric smoothing terms; edf = estimated degrees of freedom, $F$-values $=$ used to test the significance of non-parametric smoothing terms. Adjusted $\mathrm{R}^{2}$, scale estimate and sample size (n) values are shown

\begin{tabular}{|c|c|c|c|}
\hline & edf & $F$ & p-value \\
\hline \multicolumn{4}{|l|}{ Lesser kestrel } \\
\hline$s(\max$. temperature): adobe 2009 & 2.95 & 46.50 & $<0.001$ \\
\hline$s(\max$. temperature): adobe 2014 & 1.00 & 14.19 & $<0.001$ \\
\hline$s(\max$. temperature): wooden nest-box 2009 & 2.65 & 27.71 & $<0.001$ \\
\hline$s(\max$. temperature): wooden nest-box 2014 & 1.68 & 31.95 & $<0.001$ \\
\hline$s($ age $)$ & 2.98 & 138.92 & $<0.001$ \\
\hline \multicolumn{4}{|c|}{ Adj. $\mathrm{R}^{2}=0.54 ;$ scale est. $=67.87 ; \mathrm{n}=759$ (98 chicks from 28 broods $)$} \\
\hline \multicolumn{4}{|l|}{ Roller } \\
\hline$s(\max$. temperature): adobe & 1.00 & 0.47 & 0.491 \\
\hline$s(\max$. temperature): wooden nest-box & 2.38 & 25.02 & $<0.001$ \\
\hline$s($ age $)$ & 2.89 & 58.79 & $<0.001$ \\
\hline Adj. $\mathrm{R}^{2}=0.516 ;$ scale est. $=50.34 ; \mathrm{n}=335$ & & & \\
\hline
\end{tabular}

Fig. A1. Relationship between heterophil/ lymphocyte (H/L) ratios (ln-transformed) and (A) maximum nest temperature $\left({ }^{\circ} \mathrm{C}\right) 24 \mathrm{~h}$ before blood sampling $(\mathrm{p}<0.001)$ and $(\mathrm{B})$ nestling residual body mass $(\mathrm{g})$, calculated as the residuals of a regression of wing length on body mass $(\mathrm{p}<0.001)$
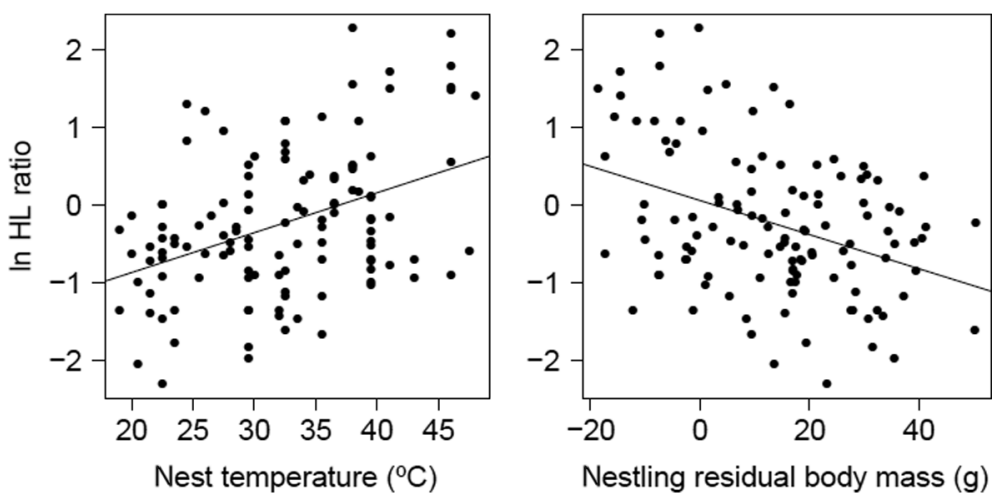

Editorial responsibility: Tim Sparks, Cambridge, UK
Submitted: February 4, 2015; Accepted: July 15, 2015

Proofs received from author(s): August 24, 2015 